\title{
Tuning the Triplet Energy Level of Pyrazolone Ligands to Match ${ }^{5} \mathrm{D}_{0}$ of $\mathrm{Eu}(\mathrm{III})$
}

Mei Shi, ${ }^{\dagger}$ Fuyou Li, ${ }^{* \dagger}$ Tao Yi, ${ }^{\dagger}$ Dengqing Zhang, ${ }^{\dagger}$ Huaiming Hu, ${ }^{*}$ Chunhui Huang $*^{\dagger}$

Laboratory of Advanced Materials, Fudan University, Shanghai, 200433, and

Department of Chemistry, Northwest University, Xi'an, 710069, P. R. China.

Supporting information

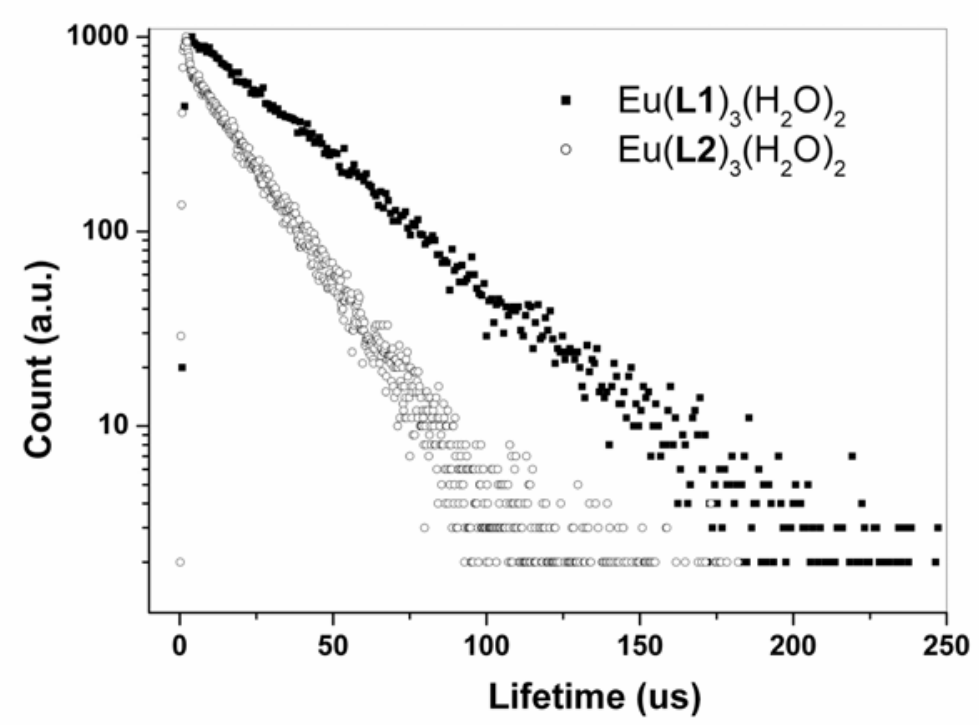

Supporting Figure 1. The decay lifetimes of $\mathrm{Eu}(\mathbf{L 1})_{3}\left(\mathrm{H}_{2} \mathrm{O}\right)_{2}$ and $\mathrm{Eu}(\mathbf{L 1})_{3}\left(\mathrm{H}_{2} \mathrm{O}\right)_{2}$ at $298 \mathrm{~K}$ 


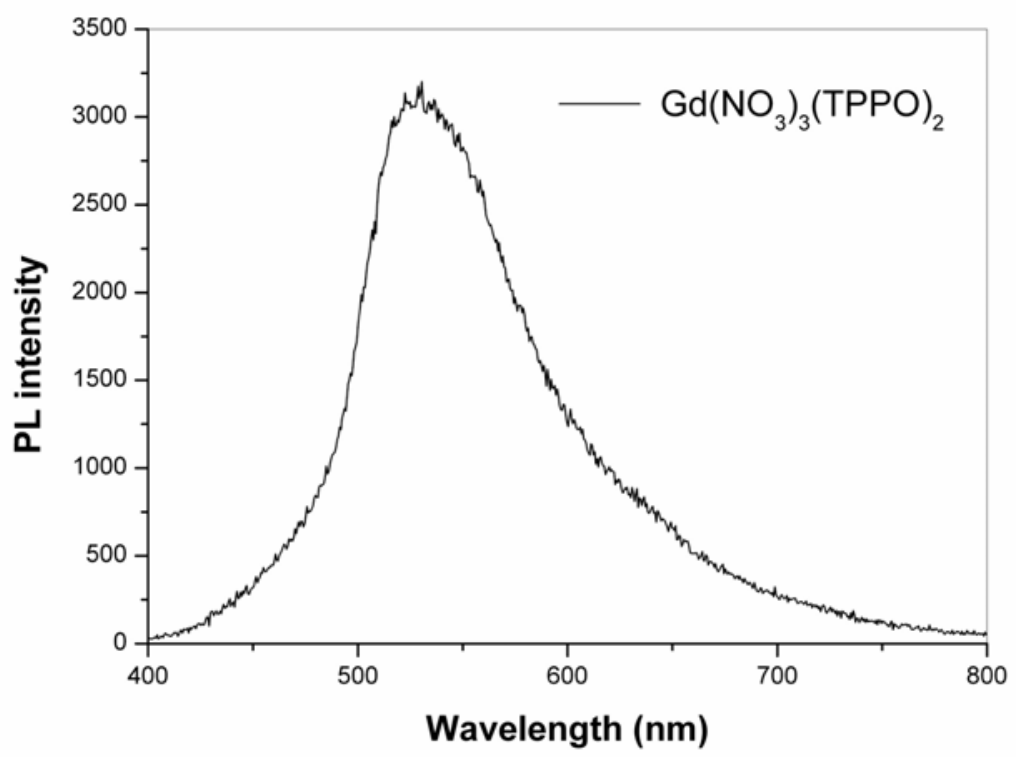

Supporting Figure 2. The phosphorescent spectra of $\mathrm{Gd}\left(\mathrm{NO}_{3}\right)_{3}(\mathrm{TPPO})_{2}$. 